\title{
LCL Filter Design and Performance Analysis for Small Wind Turbine Systems
}

\author{
A. Reznik ${ }^{*}$, M.Godoy Simões ${ }^{*}$, Ahmed Al-Durra ${ }^{* *}$, S. M. Muyeen ${ }^{* *}$ \\ *Colorado School of Mines, EECS Depart., Golden, CO, USA \\ ***ectrical Engineering Department, The Petroleum Institute, Abu Dhabi, UAE.
}

\begin{abstract}
The use of power converter is becoming very popular nowadays to maximize the power extraction from wind as well as interfacing the wind generator with the power grid. LCL filter plays an important role for interconnecting the inverter to the utility grid. Although several researchers designed LCL filtering based inverters, it has been still lacking in the literature a consisted and systematic design methodology that considers statespace mathematical models for delta and wye connected capacitors, considering grounding options and related harmonics mitigation. This paper discusses a comprehensive design of the output LCL filter for the grid-interconnected inverters used in small scale wind energy conversion system, with a practical industrial point of view. The proposed design methodology can also be used in medium and large scale grid connected wind and photovoltaic systems. This paper has practical applicability by describing all the procedural methodology and analysis in how to design LCL filters supported by an in-depth simulation study.
\end{abstract}

Index Terms--Filter; harmonics; inverter; power quality; pulsewidth-modulated(PWM) inverters;

\section{INTRODUCTION}

$\mathrm{D}$ UE to the space limitations and lower levels of primary energy resources, renewable-based distributed generation (DG) technologies in urban areas are usually implemented as micro and small-scale systems.

There has been a huge increase in energy demand, during the last few decades, which has accelerated the depletions of world fossil fuel supplies. Environmental concerns and international policies are supporting new interests and developments for small - scale power generations [1], [2].

Microgeneration is the small-scale generation of heat and electric power by individuals, small businesses and communities to meet their own needs, as alternatives or supplements to traditional centralized grid-connected power. Although this may be motivated by practical considerations, such as unreliable grid power or long distance from the electric grid, the term is mainly used currently for environmentally-conscious approaches that aspire to zero or low-carbon footprints [3]. Small-scale wind power is the name given to wind generation systems with the capacity to produce up to $50 \mathrm{~kW}$ of electrical power. Isolated communities, that may otherwise rely on diesel generators, may use wind turbines as an alternative. Individuals may purchase these systems to reduce or eliminate their dependence on grid electricity for economic reasons, or to reduce their carbon footprint. Wind turbines have been used for household electricity generation in conjunction with battery storage over many decades in remote areas [4].
Grid-connected domestic wind turbines may use grid energy source, thus displacing purchased electricity with locally produced power when available. The surplus power produced by domestic microgenerators can, in some jurisdictions, be fed into the network and sold to the utility company, producing a retail credit for the microgenerators owners to offset their energy costs [5]. Off-grid system users can either adapt to intermittent power or use batteries, photovoltaic or diesel systems to supplement the wind turbine. Equipment such as parking meters, traffic warning signs, street lighting, or wireless Internet gateways may be powered by a small wind turbine, possibly combined with a photovoltaic system, that charges a small battery replacing the need for a connection to the power grid.

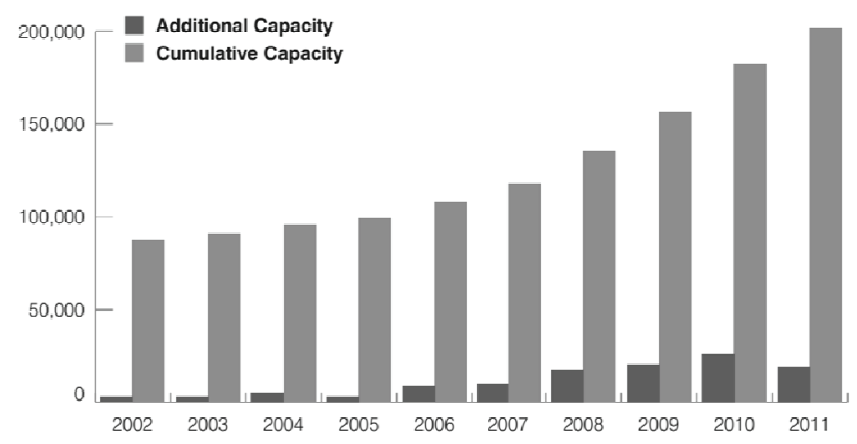

Fig. 1: Additional and Cumulative Capacity of Small Wind Turbines (kW,US)

In 2011 the U.S. small wind industry represents combined domestic sales and exports were $33 \mathrm{MW}$, a 13.4 percent increase over 2010. Total U.S. cumulative sales (including imports) reached $198 \mathrm{MW}$, representing 151,300 total units installed in the United States in 2011. In 2011, the U.S. small wind market declined by 26 percent, with $19 \mathrm{MW}$ of new sales capacity (representing 7,303 turbines) and \$115 million in installed system revenue. The trend of additional and cumulative capacity is shown on Fig.1 [6]. As a result of the poor economy and inconsistent incentives, sales revenues declined by 17 percent, with units sold down by 6.5 percent[6].

In general, the industry expects a rebound and increased 2012 sales as the economy improves, state incentive programs are refreshed and certified turbines are installed as U.S. certification programs progress. The U.S. small wind industry represents an estimated 1,600 full-time equivalent jobs, including recent increases related to exports from U.S. manufacturers. U.S. small wind installations annually displace 
178,000 metrictons of carbon dioxide (equivalent to removing 31,000 cars from service) [6].

For making purpose of small, medium, or large scale wind turbines, grid code is an important issue to be considered. Grid codes of wind turbine vary from country to countries and there are many countries yet to be developed the grid code. Therefore, wind turbine manufacturers face difficulty and need to come up with a moderate approach to comply with the standards which suit to all regions. As a result, filter designing has vital importance for the grid connection of wind turbine generator systems in order to mitigate harmonics.

At the present, variable speed wind turbine generator systems hold the major market share. Today most small wind turbines use direct driven permanent magnet generators or asynchronous generators [5]. Direct driven switched reluctance generator will also be popular in near future [6]. For the small variable speed wind turbines, a three-phase or single-phase grid-connected voltage source inverter(VSI) is needed to interface between the output of a wind turbine generator and electric power grid. Since the wind turbine system can only follow the voltage of the grid a as required by interconnection standards [7], its power quality mainly depends on inverter output current. To meet the IEEE interconnections standards, the current control of gridconnected VSIs output filter play important role in feeding a grid with high quality power [8].

Voltage source inverters (VSI) are almost exclusively used for the energy transfer and utilization from a DC source to the utility grid in our case. In order to interface power sources to the power grid, it is necessary to have a filter to impose a current-like feedback control and reduce harmonics of the injected output current. A series inductor can be used as such filter, but it highly depends on switching frequency and harmonic attenuation levels, causing high voltage drop over the grid frequency along bulky components [9].

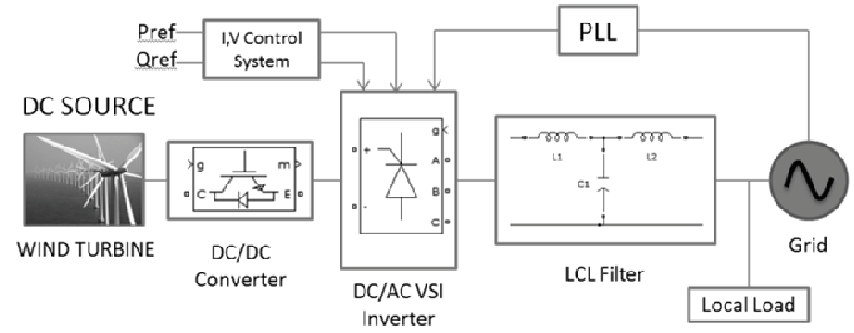

Fig. 2: Grid Interconnected DC Power Source

The LCL filter is a good alternative to achieve a higher attenuation and cost reduction, in addition to improved weight and size. Since a high order LCL filter has commonly been used in place of the conventional L-filter to give a better smoothing of output currents from a VSI [9], [10], it has been observed that there is a gap in the analysis and evaluation of LCL filters for a systematic design methodology [11], [12]. It is a core requirement for grid-connected inverters and pulsewidth modulated active rectifiers [9]-[13], mainly due to its ability to minimize the amount of current distortion injected into the utility grid [14]. The higher harmonic attenuation of the LCL filter allows the use of lower switching frequencies to meet harmonic as defined by standards such as, IEEE-5191992 and IEEE-1547 [15],[7]). Good performance can be obtained in the range of power levels up to hundreds of $\mathrm{kW}$, still using quite small values of inductors and capacitors [13]. In order to design a good LCL filter it is necessary to have appropriate mathematical model of the filter. In this paper, the output filter model, filter design procedure and the passive damping design will be systematically discussed.

A lot of work has been done regarding small wind turbines and their application [1], [2]. The aim of this paper is to offer a comprehensive analysis and modeling of the three-phase LCL filter for transformerless inverter suitable for wind energy application with respect to the grounding relevant issues. Two topologies of the three-phase full-bridge dc/ac inverter, which is one of the simplest and most widely used topology of VSI are compared: with wye connected filter capacitors and damping resistors, the second one delta connected filter capacitors and resistors.

\section{System ModelinG}

\section{A. Per Phase Model}

The LCL filter per-phase model is shown in Fig. 3 where $L_{1}$ is the inverter side inductor, $L_{2}$ is the grid side inductor, $C_{f}$ is the capacitor of LCL filter and $R_{f}$ is the damping resistor, $R_{g}$ is the grid resistance. $V_{i}$ and $V_{g}$ are input and output voltages of inverter bridge.

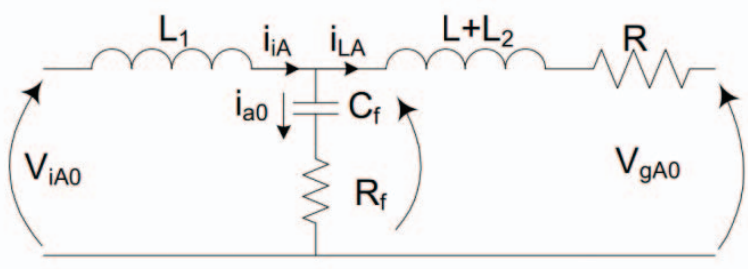

Fig. 3: LCL Filter per Phase Model

The currents $i_{i A}, i_{a 0}, i_{L A}$ are inverter output current, capacitor current and grid current, respectively. There are two possible configuration of LCL filter which will be discussed in next sections.

\section{B. Wye Connected Capacitors}

The LCL filter state space model with wye connected capacitors is derived from per phase model as shown on Fig.3 with the assumption that the damping resistance $\left(R_{f}\right)$ is zero.

$$
\begin{aligned}
& \left\{\begin{array}{c}
\frac{d V_{A 0}}{d t}=\frac{i_{i A}-i_{L A}}{C_{f}} \\
\frac{d i_{1}}{d t}=\frac{1}{L_{1}}\left(V_{i A 0}-V_{A 0}\right) \\
\frac{d i_{L A}}{d t}=\frac{1}{L_{2}+L}\left(V_{A 0}-R i_{L A}-V_{g A 0}\right)
\end{array}\right. \\
& \dot{x}=A x+B u \\
& V_{L A 0}=V_{A 0}-L_{2} \frac{d i_{2}}{d t}=\mathrm{V}_{\mathrm{A} 0}\left(\frac{L}{L_{2}+L}\right)+i_{2} \frac{R L_{2}}{L_{2}+L}+V_{g} \frac{L_{2}}{\left(L_{2}+L\right)} \\
& y=C x+D u
\end{aligned}
$$




$$
\left[\begin{array}{c}
\mathrm{i}_{\mathrm{LA}} \\
\mathrm{V}_{\mathrm{LA} 0}
\end{array}\right]=\left[\begin{array}{ccc}
0 & 0 & 1 \\
\frac{\mathrm{L}_{3}}{\mathrm{~L}_{2}+\mathrm{L}} & 0 & \frac{\mathrm{RL}_{2}}{\mathrm{~L}_{2}+\mathrm{L}}
\end{array}\right] *\left[\begin{array}{c}
\mathrm{V}_{\mathrm{A} 0} \\
\mathrm{i}_{1} \\
\mathrm{i}_{2}
\end{array}\right]+\left[\begin{array}{cc}
0 & 0 \\
0 & \frac{\mathrm{L}_{2}}{\mathrm{~L}_{2}+\mathrm{L}}
\end{array}\right] *\left[\begin{array}{c}
\mathrm{V}_{1} \\
\mathrm{~V}_{\mathrm{g}}
\end{array}\right]
$$

\section{Delta Connected Capacitors}

A LCL filter with delta connected capacitors can be analyzed in the $a b c$ stationary frame with the circuit of Fig.4. Voltages and currents can be formulated as (6) and (7).

$$
\begin{gathered}
V_{A B}+V_{B C}+V_{C A}=0 \\
\frac{d V_{A B}}{d t}=\frac{1}{3 C} i_{i A B}-\frac{1}{3 C} i_{L A B}
\end{gathered}
$$

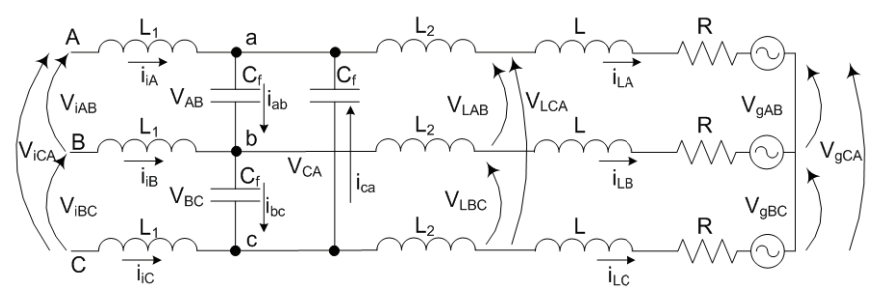

Fig. 4: LCL Filter with Delta Connected Capacitors

where $i_{i A B}=i_{i A}-i_{i B}$ and $i_{L A B}=i_{L A}-i_{L B}$

Equation (6) is the voltage balance around the capacitor, and the load side equations are supported by (8)-(10) with corresponding matrix form in (11).

$$
\begin{gathered}
\frac{d i_{i A B}}{d t}=-\frac{1}{L_{1}} V_{A B}+\frac{1}{L_{1}} V_{i A B} \\
\frac{d i_{L A B}}{d t}=-\frac{R}{L_{2}+L_{g}} i_{L A B}+\frac{1}{L_{2}+L_{g}} V_{A B}-\frac{1}{L_{2}+L} V_{g A B} \\
V_{L A B}=V_{A B}-\frac{L_{2} V_{A B}}{L_{2}+L_{g}}+L_{2} R \frac{i_{L A B}}{L_{2}+L_{g}}+V_{g A B} \frac{L_{2}}{L_{2}+L_{g}}= \\
=V_{A B}\left(\frac{L}{L_{2}+L_{g}}\right)+i_{L A B} \frac{L_{2} R}{L_{2}+L_{g}}+V_{g A B} \frac{L_{2}}{L_{2}+L_{g}} \\
\left\{\begin{array}{c}
\frac{d V}{d t}=\frac{1}{3 C_{f}} I_{i}-\frac{1}{3 C_{f}} I_{L} \\
\frac{d I_{i}}{d t}=-\frac{1}{L_{1}} V+\frac{1}{L_{1}} V_{i} \\
\frac{d I_{L}}{d t}=-\frac{R}{L_{2}+\mathrm{L}} \mathrm{I}_{\mathrm{L}}+\frac{1}{\mathrm{~L}_{2}+\mathrm{L}} \mathrm{V}-\frac{1}{\mathrm{~L}_{2}+\mathrm{L}} \mathrm{V}_{\mathrm{g}}
\end{array}\right.
\end{gathered}
$$

where $V=\left[V_{A B} V_{B C} V_{C A}\right]^{T}, I_{i}=\left[i_{i A B} i_{i B C} i_{i C A}\right]^{T}$,

$$
V_{i}=\left[V_{i A B} V_{i B C} V_{i C A}\right]^{T}, \quad I_{L}=\left[i_{L A B} i_{L B C} i_{L C A}\right]^{T}
$$

Finally, the plant model as a continuous state-space equation:

$$
\text { where } A=\left[\begin{array}{ccc}
0_{3 \times 3} & \frac{1}{3 C_{f}} I_{3 \times 3} & -\frac{1}{3 C_{f}} I_{3 \times 3} \\
-\frac{1}{L_{1}} I_{3 \times 3} & 0_{3 \times 3} & 0_{3 \times 3} \\
\frac{1}{L_{2}+L} I_{3 \times 3} & 0_{3 \times 3} & -\frac{R}{L_{2}+L} I_{3 \times 3}
\end{array}\right]_{9 \times 9} \text {, }
$$

$$
B=\left[\begin{array}{c}
0_{3 \times 3} \\
\frac{1}{L_{1}} I_{3 \times 3} \\
-\frac{1}{L_{2}+L} I_{3 \times 3}
\end{array}\right]_{9 \times 3}, u=\left[\begin{array}{l}
V_{i} \\
V_{g}
\end{array}\right]_{6 \times 1}, X=\left[\begin{array}{c}
V \\
I_{i} \\
I_{L}
\end{array}\right]_{9 \times 1}
$$

\section{Frequency Response and Transfer Function}

From the developed mathematical models, transfer functions of LCL filter can be derived. One of the extracted transfer function from derived state space equations is $H_{L C L}=\frac{i_{g}}{v_{i}}$. The grid voltage is assumed to be an ideal voltage source and it represents a short circuit for harmonic frequencies, and for the filter analysis is set to zero: $v_{g}=0$. So, the transfer function of LCL filter without damping is:

$$
H_{L C L}(s)=\frac{1}{L_{1} C_{f}\left(L_{2}+L\right) s^{3}+\left(L_{1}+L_{2}+L\right) s}
$$

for damped filter:

$$
H d_{L C L}(s)=\frac{C_{f} R_{f} s+1}{L_{1} C_{f}\left(L_{2}+L\right) s^{3}+C_{f}\left(L_{1}+L_{2}+L\right) R_{f} s^{2}+\left(L_{1}+L_{2}+L\right) s}
$$

The bode plots of LCL filter without and with damping is described in Section III are shown in Fig. 5.

\section{Filter Design Procedure}

\section{A. Step By Step Design}

Important constraints must be taken in consideration in the design of LCL filters, such as current ripple, filter size, switching ripple attenuation. The reactive power variation seen by the grid because of the capacitor may give a resonance that could lead to unstable operation of the system. Therefore, passive or active damping is proposed by either adding a resistor in series with capacitor or changing the controller design[9]. Here will be used only passive damping technique.

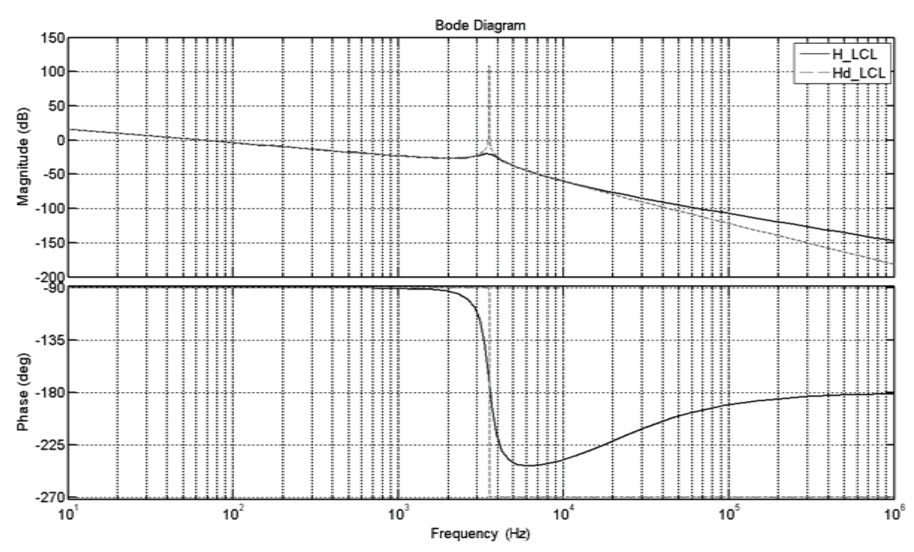

Fig. 5: Step Response Bode Diagram for Damped and Undamped Cases

The LCL filter is more efficient than a simple inductor (L) because the latter has only attenuation of $20 \mathrm{~dB} /$ decade for all the range of frequency [9]-[13],[16]. The switching frequency of inverter must be high enough for a correct attenuation of high current harmonics. The higher the switching frequency 
there are more losses. LC filters suffer from variability of resonance frequency over time like the grid inductance; therefore it is not appropriate for a weak grid [17].

In this study, the filter design approach has been explained step-by-step and if correctly damped, it is possible to avoid resonance problems passively [10] or actively [13]. The procedure for choosing the LCL filter parameters requires the power rating of the converter, the grid frequency and the switching frequency as inputs. Algorithm of LCL filter design is shown in Fig. 4, each step of which will be described in following sections and will be supported by filter design example.

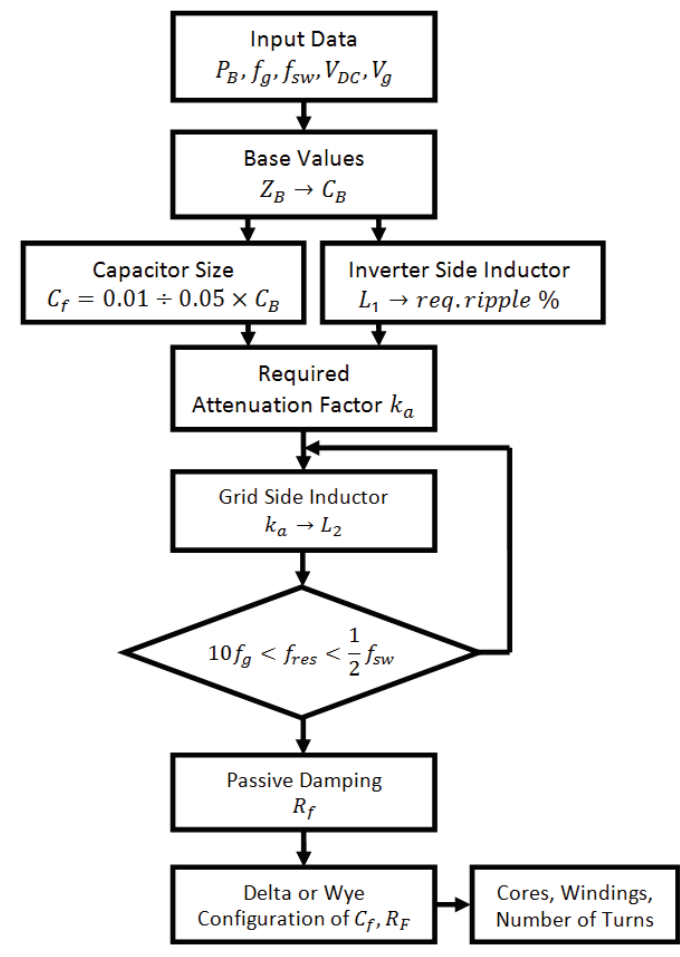

Fig. 6: LCL filter design algorithm

The following parameters are needed for the filter design: $E_{n}$-line to line RMS voltage (inverter output), $V_{p h}$-phase voltage (inverter output), $P_{n}$ - rated active power, $V_{D C}$-DC bus voltage, $f_{\mathrm{g}}$-grid frequency, $f_{s w}$-switching frequency, $f_{\text {res }}$ resonance frequency.

The base impedance and base capacitance are defined by (14) and (15). Thus, the filter values will be referred in \% of the base values:

$$
\begin{gathered}
Z_{b}=\frac{E_{n}^{2}}{P_{n}} \\
C_{b}=\frac{1}{\omega_{n} Z_{b}}
\end{gathered}
$$

For the design of the filter capacitance, it is considered that the maximum power factor variation seen by the grid is $5 \%$, as it is multiplied by the value of base impedance of the system: $C_{f}=0.05 C_{b}$ It is important to notice that factors higher than $5 \%$ can be used, since they will compensate the inductive reactance of the inductors on the filter and therefore the influence at the power factor of the system will be lesser than expected. The maximum current ripple at the output of $\mathrm{DC} / \mathrm{AC}$ inverter is [18]:

$$
\Delta I_{L \max }=\frac{2 V_{D C}}{3 L_{1}}(1-m) m T_{s w}
$$

where, $m$ - modulation factor.

It can be observed that maximum peak to peak current ripple happens at $m=0.5$, then

$$
\Delta I_{L \max }=\frac{V_{D C}}{6 f_{S w} L_{1}}
$$

where $L_{1}$ is inverter side inductor. A $10 \%$ ripple of the rated current for the design parameters is given by:

$$
\Delta I_{\text {Lmax }}=0.1 I_{\max }
$$

where

$$
\begin{gathered}
I_{\max }=\frac{P_{n} \sqrt{2}}{3 V_{p h}} \\
L_{1}=\frac{V_{D C}}{6 f_{S W} \Delta I_{L \max }}
\end{gathered}
$$

The main objective of the LCL filter design is in fact to reduce the expected $10 \%$ current ripple limit to $20 \%$ of its own value, resulting in a ripple value of $2 \%$ of the output current [10], [15]. In order to calculate the ripple reduction, the LCL filter equivalent circuit is firstly analyzed considering the inverter as a current source for each harmonic frequency Fig.3.

Equations (21) and (22) give the relation between the harmonic current generated by the inverter and the once injected in the grid:

$$
\frac{i_{g}(h)}{i_{i}(h)}=\frac{1}{\left|1+r\left[1-L_{1} C_{b} \omega_{s w}^{2} x\right]\right|}=k_{a}
$$

or

$$
L_{2}=\frac{\sqrt{\frac{1}{k_{a}^{2}}}+1}{C_{f} w_{s w}^{2}}
$$

where, $k_{a}$ is desired attenuation. $C_{f}=0.01 \div 0.05 C_{b}$

The constant $r$ is defined as the relation between the inductance at the inverter side and the one at the grid side:

$$
L_{2}=r L_{1}
$$

Plotting for different $r$ one can evaluate the transfer function of the filter at a particular resonant frequency that depends on the nominal grid impedance [14]. A resistor in series $\left(R_{f}\right)$ with the capacitor attenuates part of the ripple on the switching frequency in order to avoid the resonance. The value of this resistor should be one third of the impedance of the filter capacitor at the resonant frequency [19] and the resistor in series with the filter capacitance is given by (26). 


$$
\begin{gathered}
\omega_{\text {res }}=\sqrt{\frac{\mathrm{L}_{1}+\mathrm{L}_{2}+\mathrm{L}}{\mathrm{L}_{1} \mathrm{~L}_{2} \mathrm{C}_{\mathrm{f}}}} \\
10 f_{g}<f_{\text {res }}<0.5 f_{s w}
\end{gathered}
$$

It is necessary to check resonant frequency to satisfy (25). If it does not, the parameters should be re-chosen.

$$
R_{f}=\frac{1}{3 \omega_{\text {res }} C_{f}}
$$

\section{B. Delta or Wye Configuraiton}

After defining all parameters for LCL filter two configuration are possible for implementation. Parameters defined in Section A are valid for wye capacitors connection, however using simple and well known wye delta transformation for balanced system wye configuration can be transformed to delta:

$$
Z_{A B}=\frac{Z_{A}}{3}
$$

It's obvious from (28), that for delta configuration size of capacitor should be three times smaller than for wye configuration and vice versa for damping resistance:

$$
\begin{gathered}
R_{f_{\Delta}}=3 R_{f_{Y}} \\
C_{f_{\Delta}}=\frac{C_{f_{Y}}}{3}
\end{gathered}
$$

It is common practice to ground neutral, or central point of wye connection [20]. In most cases, this grounding is required by the U.S. National Electric Code (NFPA-70). By grounding a wye system, the voltages to ground are stabilized and controlled. This makes system much less susceptible to impulses, and faults that cause high voltages to ground. In case of delta configuration there are no questions and problems with grounding. That's why author's propose delta connection as more convenient and less questionable way to get same good performance of LCL filter.

\section{FILTER DESIGN EXAMPLE}

A step by step procedure to obtain parameters of the filter with wye configuration considering the following given data, needed for the filter design: $E_{n}=120 \sqrt{3} V$ - line to line RMS voltage, $P_{B}=P_{n}=5 \mathrm{~kW}$ - rated active power, $V_{D C}=400 \mathrm{~V}$ DC bus voltage, $\omega_{\mathrm{n}}=2 \pi 60$-grid frequency, $\omega_{s w}=15 \mathrm{kHz}-$ switching frequency, $x=0.05$ - maximum power factor variation seen by the grid, $k_{a}=0.2(20 \%)$ - attenuation factor is done. Therefore, the base impedance and the base capacitance are $Z_{B}=8.64 \Omega, C_{B}=307 \mu F$ respectively (parameters are shown in Table I).

1. Using $10 \%$ allowed ripple equation (17) gives inductance $L_{1}=2.23 \mathrm{mH}$
2. Maximum capacitor value is $16.63 \mu F$ to be in limit of $5 \%$ of the base value $C_{B}$. After rounding to closest possible value $C_{f}=15 \mu \mathrm{F}$.

3. Setting desired attenuation $k_{a}=20 \%$ and using (22) $L_{2}$ is calculated to be $0.045 \mathrm{mH}$

4. Putting all calculated parameters from (1)-(3) to (23) gives $f_{\text {res }}=6450 \mathrm{kHz}$ which is meets condition from (24)

5. Equation (25) gives value of damping resistance $R_{f}=0.55 \Omega$

6. Inductors parameters are defined using the software available on web site of Magnetics ${ }^{\circledR}$ Company and presented in Table II.

TABLE I. TESTED SYSTEM PARAMETERS

\begin{tabular}{|c|l|l|}
\hline$f_{g}$ & Grid frequency & $60 \mathrm{~Hz}$ \\
\hline$f_{S W}$ & PWM carrier frequency & $15 \mathrm{kHz}$ \\
\hline$P_{n}$ & Nominal Power & $5 \mathrm{~kW}$ \\
\hline$V_{g}$ & Phase grid voltage & $120 \mathrm{~V}$ \\
\hline$V_{D C}$ & DC link Voltage & $400 \mathrm{~V}$ \\
\hline$L_{1}$ & Inverter side inductor & $2.33 \mathrm{mH}$ \\
\hline$L_{2}$ & Grid side inductor & $0.045 \mathrm{mH}$ \\
\hline$C_{f}$ & Capacitor filter $Y / \Delta$ & $15 \mu \mathrm{F} / 5 \mu \mathrm{F}$ \\
\hline$R_{f}$ & Damping Resistor $Y / \Delta$ & $0.55 \Omega / 1.65 \Omega$ \\
\hline
\end{tabular}

TABLE II. INDUCTORS PARAMETERS

\begin{tabular}{|l|l|l|}
\hline Parameter & \multicolumn{1}{|c|}{$L_{1}$} & \multicolumn{1}{c|}{$L_{2}$} \\
\hline Inductance $(\mathrm{mH})$ & $2.33 \mathrm{mH}$ & $0.045 \mathrm{mH}$ \\
\hline Core Type & $77102-\mathrm{A} 7$ & $77258-\mathrm{A} 7$ \\
\hline Number in Stack & 5 & 1 \\
\hline Wire & AWG 12 & AWG 12 \\
\hline Number of Turns & 116 & 43 \\
\hline
\end{tabular}

\section{SimUlation RESUlts AND ANALYSIS}

\section{A. System Modeling}

For the sake of simplicity the wind generator dynamics including generator side converter are ignored assuming the DC-link voltage is constant as focus is given on the grid side dynamics. The model has been built using Matlab ${ }^{\circledR}$ and Simulink ${ }^{\circledR}$ Power System ToolBox environment as shown in Fig.7. Sampling time and simulation step size is $0.5 \mu \mathrm{s}$, sampling time for the control system is $50 \mu \mathrm{s}$. Fig. 8 shows a schematic diagram of a current-controlled real-/reactive-power controller, illustrating that the control in performed in $d q$ frame. Thus active and reactive power controlled by the line current components $i_{d}$ and $i_{q}$. The feedback and feed-forward signals are first transformed to the $d q$ - frame and then processed by compensators to produce the control signals in $d q$-frame. The active and reactive powers are calculated using measurements at the PCC and their values are compared with set-points. Then PI-based controllers decide the reference $d$ and $q$ components of the reference current. Finally, the control signals are transformed to the $a b c$-frame and fed to VSI. To protect the VSI, the reference commands $i_{\text {dref }}$ and $i_{\text {qref }}$ are limited by the corresponding saturation blocks (not shown in Fig.8) 


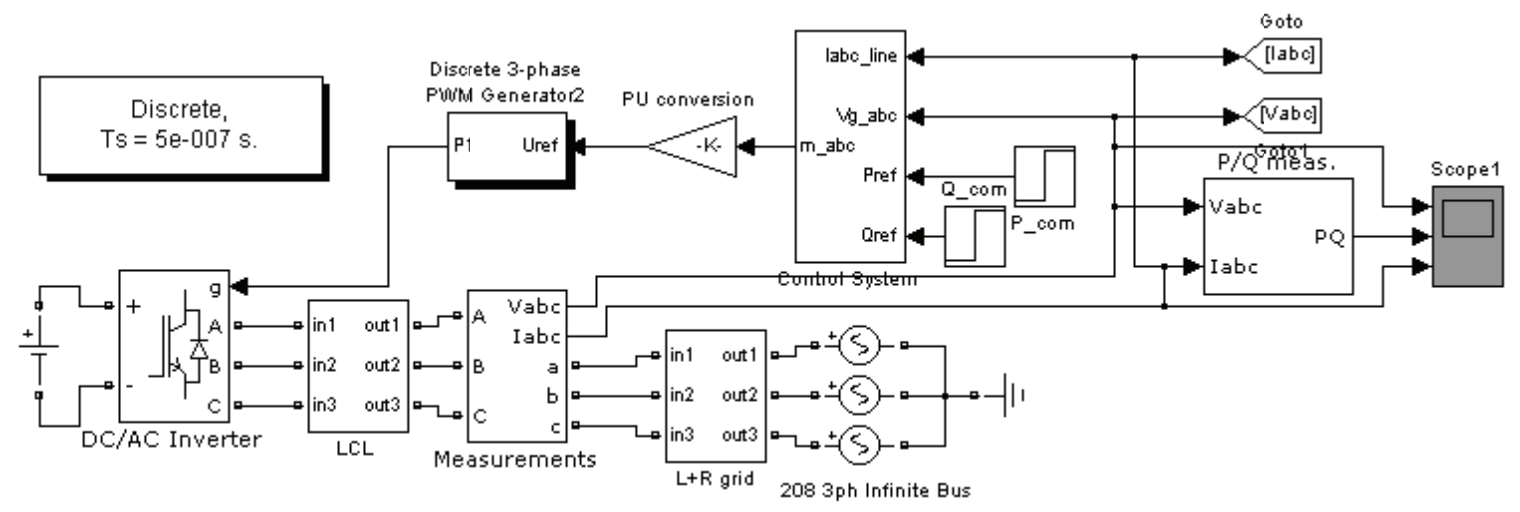

Fig. 7:Grid Connected Inverter

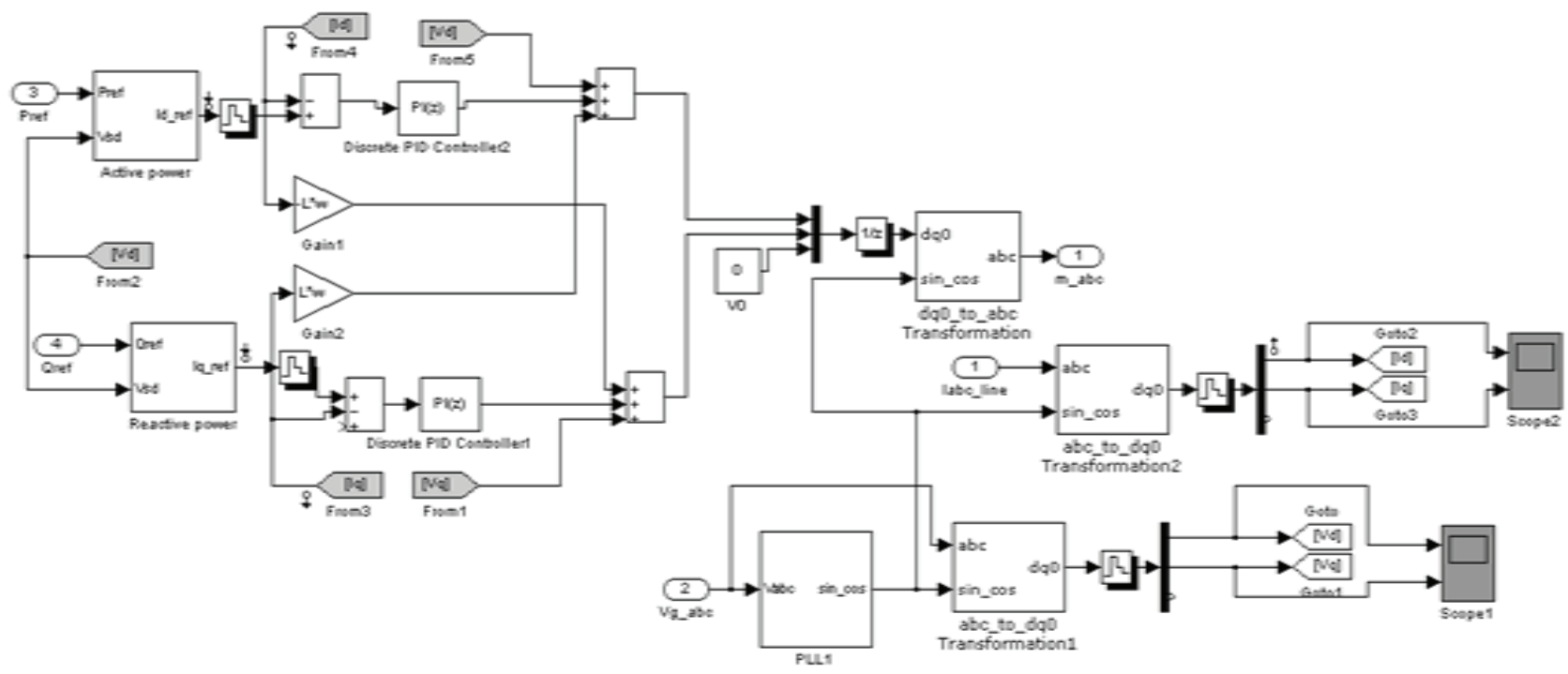

Fig. 8:Control System

\section{B. System Perfomance and Power Quality}

As it can be seen from Fig. 9 and Fig. 10, both configurations have very good performance.

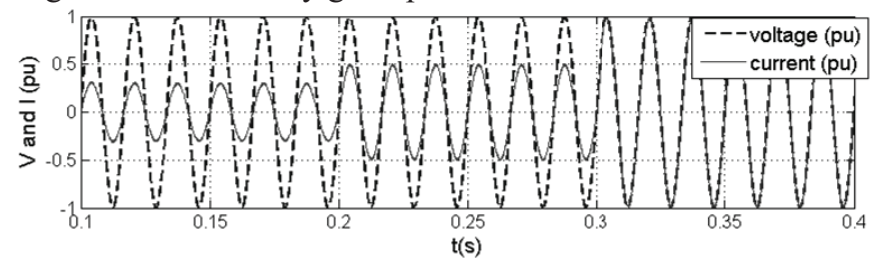

Fig. 9:Current(pu) and Voltage(pu) for Phase A

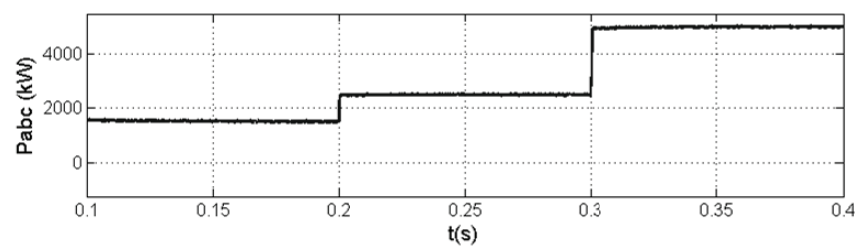

Fig. 10:Active Power Injected to the Grid

THD analysis is conducted with the help of Fast Fourier Transformation tool in Simulink and results are presented in Table III for injecting power to the grid under unity power factor condition.
TABLE III. THD RESULTS

\begin{tabular}{|l|l|l|}
\hline Active Power & Delta & Wye \\
\hline $1500 \mathrm{~kW}(0.3 \mathrm{pu})$ & $1.44 \%$ & $1.42 \%$ \\
\hline $2500 \mathrm{~kW}(0.5 \mathrm{pu})$ & $0.94 \%$ & $0.93 \%$ \\
\hline $5000 \mathrm{~kW}(1 \mathrm{pu})$ & $0.45 \%$ & $0.45 \%$ \\
\hline
\end{tabular}

THD results are within limits, as defined by[15],[7].

\section{CONCLUSION}

In order to address some difficulties from wind industry related to the integration of micro and small-scale wind inverter-based generation systems in terms of power quality and control, this paper discussed a detailed analysis of front end inverter with LCL filter. The parameter-design method of the LCL filter has been proposed for a three-phase gridconnected inverter system used in small scale wind turbine generator system. The LCL filter used to reduce the switching frequency ripple has been analyzed. The design of LCL filter should be made carefully due to the resonance and stability issues. Therefore, a comprehensive and detailed design procedure for the LCL filter has been provided and stability and dynamics of the overall system have been studied. It is found that the design meets the industry standards keeping the THD within the given range. The given design approach of 
LCL filter is also applicable with the front end inverters used in medium and large scale wind generators and photovoltaic systems as well.

\section{REFERENCES}

[1] F. A. Farret, B. Palle, and M. G. Simões, "A full expandable model of parallel self excited induction generators," in IEE Proceedings Electric Power Applications, 2005, pp. 96-102.

[2] B. Palle, M. G. Simões, S. Member, and F. A. Farret, "Dynamic Simulation and Analysis of Parallel SelfExcited Induction Generators for Islanded Wind Farm Systems," vol. 41, no. 4, pp. 1099-1106, 2005.

[3] "Microgeneration." [Online]. Available: http://en.wikipedia.org/wiki/Microgeneration.

[Accessed: 04-May-2012].

[4] D. M. Dodge, "Illustrated history of wind power development." [Online]. Available: http://telosnet.com/wind/. [Accessed: 04-May-2012].

[5] J. Kart, "Wind, Solar-Powered Street Lights Only Need a Charge Once Every Four Days," Wind, SolarPowered Street Lights Only Need a Charge Once Every Four Days, 2009. [Online]. Available: http://cleantechnica.com/2009/05/13/exploiting-thedownsides-of-wind-and-solar/. [Accessed: 04-May2012].

[6] "AWEA 2011 Small Wind Turbine Market Report Executive Summary," 2011.

[7] "1547.1 IEEE Standard Conformance Test Procedures for Equipment Interconnecting Distributed Resources with Electric Power Systems," IEEE Std 1547.1-2005, 2005.

[8] Z. Wang and L. Chang, "A DC voltage monitoring and control for three phase grid-connected wind turbine inverters," IEEE Transactions on Power Electronics, vol. 23, no. 3, pp. 1118-1125, 2008.

[9] F. Bouchafaa, D. Beriber, and M. S. Boucherit, "Modeling and control of a gird connected PV generation system," in Control \& Automation (MED), 2010 18th Mediterranean Conference, 2010, pp. 315 320.

[10] M. Liserre, F. Blaabjerg, and S. Hansen, "Design and Control of an LCL-Filter-Based Three-Phase Active Rectifier," IEEE Transactions on Industry Applications, vol. 41, no. 5, pp. 1281-1291, Sep. 2005.

[11] Y. Lang, D. Xu, S. R. Hadianamrei, and H. Ma, "A Novel Design Method of LCL Type Utility Interface for Three-Phase Voltage Source Rectifier," in Power Electronics Specialists Conference, 2005. PESC '05. IEEE 36th, 2005, pp. 313-317.

[12] Y. Tong, F. Tang, Y. Chen, F. Zhou, and X. Jin, "Design Algorithm of Grid-side LCL-filter for Threephase Voltage Source PWM Rectifier," in Power and Energy Society General Meeting - Conversion and Delivery of Electrical Energy in the 21st Century, 2008 IEEE, 2008, pp. 1-6.

[13] V. Blasko and V. Kaura, "A Novel Control to Actively Damp Resonance in Input LC Filter of a Three-Phase Voltage Source Converter," IEEE Transactions on
Industry Applications, vol. 33, no. 2, pp. 542-550, 1997.

[14] Y. Tang, S. Member, P. C. Loh, P. Wang, and F. H. Choo, "Generalized Design of High Performance Shunt Active Power Filter With Output LCL Filter," IEEE Transactions on Industrial Electronics, vol. 59, no. 3, pp. 1443-1452, 2012.

[15] "519-1992 IEEE Recommended Practices and Requirements for Harmonic Control in Electrical Power Systems," IEEE Std 519-1992, 1993.

[16] A. O. Zué and A. Chandra, "Simulation and Stability Analysis of a $100 \mathrm{~kW}$ Grid Connected LCL Photovoltaic Inverter for Industry," in Power Engineering Society General Meeting, 2006. IEEE, 2006, pp. 1-6.

[17] M. Raoufi and M. T. Lamchich, "Average current mode control of a voltage source inverter connected to the grid: Application to different filter cells," Journal of Electrical Engineering, vol. 55, no. 3, pp. 77-82, 2004.

[18] V. H. Prasad, "Average current mode control of a voltage source inverter connected to the grid: Application to different filter cells," Master's Thesis, Dept. Electrical Engineering., Virginia Tech, Blacksburg, Virginia, 1997.

[19] S. V. Araújo, A. Engler, B. Sahan, V. U. Kassel, F. Luiz, and M. Antunes, "LCL Filter design for gridconnected NPC inverters in offshore wind turbines," in The 7th International Conference on Power Electronics, 2007, pp. 1133-1138.

[20] "142-2007 - IEEE Recommended Practice for Grounding of Industrial and Commercial Power Systems," IEEE Std 142-2007, 2007. 